\title{
Effect of Age and Socio-Economic Status on Compliance among Type 2 Diabetic Patients
}

\author{
Farah Habib* and Anisa M Durrani \\ DDepartment of Home Science, India
}

Submission: May 03, 2018 Published: May 30, 2018

*Corresponding author: Farah Habib, PhD, Department of Home Science, AMU, Aligarh, India, Email: farahharis85@gmail.com.

\begin{abstract}
Diabetes is a chronic disease, which needs lifestyle modification for its management. Age and socioeconomic status has been linked with self-care behaviour including compliance to treatment regimen. The purpose of the present study is to find the correlation between age, socioeconomic status and diabetic compliance among type 2 diabetic patients. A representative sample of 200 type 2 diabetes patients of age between 30-60 years, with no co-morbidity were selected in OPD of Rajiv Gandhi Centre of Diabetes and Endocrinology, JNMC, Aligarh. Individual interviews were performed to gather information through diabetic compliance questionnaire-a 15 item five point likert type scale and glycemic level was measured by glycosylated hemoglobin. The Pearson correlation coefficient showed that age was correlated to dietary compliance $(r=0.139, p<0.05)$ and SES was correlated with diet $(r=0.322, p<0.01)$, exercise $(r=0.198, p<0.05)$ and glucose testing $(r=0.157, p<0.05) r e g i m e n$ compliance. It was concluded from the results that age and SES of the patient affects the level of compliance. Increasing age and high SES positively predicted the compliance to the regimen and as a result better control over the disease.
\end{abstract}

Keywords: Diabetic compliance; SES; Glycemic level; HbA1c.

\section{Introduction}

Diabetes mellitus is a chronic disease that deteriorates health and quality of life. Presently, about 422 million people worldwide are affected by this disease [1]. It is also alarmingly increasing and gaining the status of potential epidemic in India with more than 69.2 million diabetic individuals reported with the disease as per International Diabetes Federation Atlas [2] and about $80 \%$ to $90 \%$ of cases are of type 2 diabetes mellitus [2]. Compliance to the recommended regimen is only way to manage the disease, despite this fact, non-compliance rates are high in many treatment programs including those for chronic illnesses [3], as well as for primary intervention strategies such as diet and exercise regimes [4]. People are remaining non-compliant to the treatment regimens designed to manage chronic illness and to reduce the risks of related morbidity and mortality, and a negative outcome is a significant issue in healthcare policy making. Non-compliance as cited in many studies is a global health care problem which is more serious and costly than many disease conditions [5]. Study documented that 71.7 percent of the diabetic patients mentioned forgetfulness due to increasing age as the reason for non-compliance and $67.5 \%$ patients cited socioeconomic status as the reason for non-compliance to the treatment regimen [6]. A recent study shows positive correlation between increasing age and non-compliance [7] and it would appear from the results that non-compliance of elderly people are not unidirectional [8]. They attributed physical and economic reasons, and memory slips as causes of non-compliance. Not surprisingly, socioeconomic status also appears to be important. The poor economic background is an obstacle for getting continuous therapy. The results of many researches revealed the association of high income with high self-care ability, indicated that high income group was more engage in diabetes self- care as compare to low income and middle income group patients [9$11]$.

\section{Objective}

To examine the relationship between age, socioeconomic status and diabetic compliance and its effect on glycemic level measured by glycosylated Hemoglobin (HbA1c) among type 2 diabetic patients.

\section{Methodology}

\section{Locale}

Rajiv Gandhi Centre for Diabetes and Endocrinology, Jawaharlal Nehru Medical College, Aligarh Muslim University, Aligarh.

\section{Sample and sampling method}

Sample was selected through purposive sampling method with certain inclusion criteria as follows:

A. Patients of either sex who were diagnosed with type 2 diabetes in between 30 to 60 years of age were selected. 


\section{Current Research in Diabetes \& Obesity Journal}

B. Only patients with minimum six months of type 2 diabetes history prior to study were included in the sample.

C. Type 2 diabetic patients with no co-morbidities.

D. Regular visitor/patients of the hospital affirming their willingness to participate in the study were included.

Only 200 sample patients were available in six months period according to the inclusion criteria.

\section{Interview cum schedule}

Schedule consists of general information and compliance questionnaire to assess the frequency of compliance in four regimen areas i.e. diet (nine items), exercise (two items), blood glucose testing (two items), medication (two items). This scale requires responses on a five point likert-type scale, ranging from 1 (never) to 5 (at least once a day). Scores were calculated by summing up all the items scores. Negative items were reversely coded. Higher scores indicate higher compliance while lower score are for lesser compliance. Age of the patients was asked at the time of interview and efforts were made to ascertain it with the age written in patient's record file. Socio economic status was graded according to the Kuppuswamy method of social classification modified as per price index of 2014. Glycosylated Hemoglobin was used as an index for glycemic level. HbA1c data were obtained from the patient record file. The most recent value of $\mathrm{HbA1c}$ was recorded for analysis. It was graded high, optimal and low according to the range provided by International Diabetes Federation [2].

\section{Statistical Analysis}

Data were expressed as percentage and frequencies or mean and standard deviation. Pearson correlation coefficients were used to find the correlation between age, SES and compliance. Linear regression analysis was used to find the contribution of age and SES in compliance. Throughout all analyses performed, a confidence interval of $95 \%$ and a p-value of 0.05 were used to determine statistical significance. SPSS version 20 was used for the analysis.

\section{Results}

\section{Demographic information}

The sample comprised of 200 patients, out of total 101 (50.5\%) patients were males and 99 (49.5\%) were females. Regarding age, 44 (22\%) patients were in early (30-40 years), $72(36 \%)$ in middle (40-50 years) and 84 patients (42\%) were in late (50-60 years) age years. With regard to socioeconomic status of the sample, the data obtained showed that most of the subjects were from upper middle class 101(50.5\%), 49(24.5\%) were from lower middle, 23(11.5\%) patients from upper middle, $21(10.5 \%)$ were from upper class and only $6(3 \%)$ patients belonged to lower SES. The grouping was based on Kuppuswamy socioeconomic classification (2014).

Table 1: Distribution of patients according to age on compliance and their mean $\mathrm{HbA} 1 \mathrm{c}$ level.

\begin{tabular}{|c|c|c|c|c|c|c|c|c|c|}
\hline \multirow{3}{*}{ Compliance } & \multicolumn{3}{|c|}{ 30-40 Years (Early) } & \multicolumn{3}{|c|}{ 40-50 Years (Middle) } & \multicolumn{3}{|c|}{ 50-60 Years (Late) } \\
\hline & \multirow{2}{*}{$\%$ of Patients } & \multicolumn{2}{|c|}{ HbA1c (in \%) } & \multirow{2}{*}{$\begin{array}{c}\% \text { of } \\
\text { Patients }\end{array}$} & \multicolumn{2}{|c|}{ HbA1c (in \%) } & \multirow{2}{*}{$\begin{array}{c}\% \text { of } \\
\text { Patients }\end{array}$} & \multicolumn{2}{|c|}{ HbA1c (in \%) } \\
\hline & & Mean & SD & & Mean & SD & & Mean & SD \\
\hline \multicolumn{10}{|c|}{ Dietary Regimen ( $r=0.139 *, p<0.05)$ (Regression: $\beta=0.127^{*}, R^{2}=0.114, \Delta R^{2}=0.016$ ) } \\
\hline Never & - & - & - & - & - & - & - & - & - \\
\hline Rarely & - & - & - & $1.4 \%$ & 13.0 & - & - & - & - \\
\hline Sometimes & $9.1 \%$ & 11.6 & 1.25 & $8.3 \%$ & 9.7 & 2.09 & $6 \%$ & 9.5 & 2.45 \\
\hline Usually & $52.0 \%$ & 8.0 & 1.21 & $49.4 \%$ & 8.4 & 1.5 & $45.2 \%$ & 8.4 & 1.79 \\
\hline Always & $38.9 \%$ & 7.0 & 1.17 & $40.9 \%$ & 7.7 & 1.73 & $48.8 \%$ & 7.2 & .92 \\
\hline \multicolumn{10}{|c|}{ Exercise Regimen ( $r=-0.116, p=N S$ ) (Regression: $\beta=-0.124, R^{2}=0.024, \Delta R^{2}=0.015$ ) } \\
\hline Never & $34.1 \%$ & 8.9 & 1.99 & $41.7 \%$ & 8.5 & 1.57 & $31 \%$ & 8.5 & 1.79 \\
\hline Rarely & $2.3 \%$ & 9.0 & - & $1.4 \%$ & 13 & - & $2.4 \%$ & 8.2 & 1.27 \\
\hline Sometimes & $2.3 \%$ & 8.0 & - & $8.3 \%$ & 9.2 & 2.72 & $9.5 \%$ & 8.1 & 2.10 \\
\hline Usually & $22.7 \%$ & 8.1 & 1.14 & $19.4 \%$ & 8.0 & 1.50 & $33.3 \%$ & 7.9 & 1.59 \\
\hline always & $38.6 \%$ & 6.8 & 1.18 & $29.2 \%$ & 7 & 1.77 & $23.8 \%$ & 7.3 & 1.18 \\
\hline \multicolumn{10}{|c|}{ Blood Glucose Testing Regimen ( $r=-0.039, p=N S$ ) (Regression: $\beta=-0.066^{*}, R^{2}=0.025, \Delta R^{2}=0.004$ ) } \\
\hline Never & $2.3 \%$ & 6.4 & - & - & - & - & $29.8 \%$ & 8.0 & 1.93 \\
\hline Rarely & $25.0 \%$ & 8.5 & 1.67 & $36.1 \%$ & 8.4 & 2.01 & $36.9 \%$ & 8.2 & 1.66 \\
\hline Sometimes & $43.2 \%$ & 7.7 & 1.56 & $34.7 \%$ & 8.3 & 1.77 & $11.9 \%$ & 7.5 & 1.08 \\
\hline Usually & $4.5 \%$ & 7.9 & 2.89 & $6.9 \%$ & 8.4 & .881 & $21.4 \%$ & 7.4 & 1.34 \\
\hline always & $25.0 \%$ & 7.7 & 2.02 & $22.2 \%$ & 8.4 & 1.92 & $29.8 \%$ & 8.0 & 1.93 \\
\hline
\end{tabular}




\section{Current Research in Diabetes \& Obesity Journal}

\begin{tabular}{|c|c|c|c|c|c|c|c|c|c|}
\hline \multicolumn{7}{|c|}{ Medication Regimen (r=0.009, p=NS) (Regression: $\boldsymbol{\beta}=\mathbf{0 . 1 2 9 ,} \mathbf{R}^{2}=\mathbf{0 . 0 1 0 ,} \boldsymbol{\Delta} \mathbf{R}^{2}=\mathbf{0 . 0 0 3 )}$} \\
\hline Never & - & - & - & - & - & - & - & - & - \\
\hline Rarely & - & - & - & $8.3 \%$ & 8.0 & 1.59 & $9.5 \%$ & 6.2 & .36 \\
\hline Sometimes & $4.5 \%$ & 6.5 & 0.7 & $1.4 \%$ & 11.0 & - & $1.2 \%$ & 10.8 & - \\
\hline Usually & $6.8 \%$ & 8.8 & 3.68 & $4.2 \%$ & 7.4 & .86 & $4.8 \%$ & 8.2 & 1.15 \\
\hline Always & $88.6 \%$ & 7.9 & 1.59 & $86.1 \%$ & 8.4 & 1.85 & $84.5 \%$ & 8 & 1.62 \\
\hline
\end{tabular}

Age contributed of $11.4 \%$ of variance in explaining the dietary compliance $(\mathrm{P}<0.05)$. Values in Table 1 showed that majority of the patients $(48.8 \%)$ who always follow dietary regimen were from late (51-60 years) age group followed by middle (40.9\%) and then from early (38.9\%) age group. Dietary compliance was also found significantly correlated with age $(r=0.139, \mathrm{p}<0.05)$ it showed that the aged patients complied more with the dietary regimen also.

The obtained results on exercise regimen revealed that mostly patients from early (30-40) age groups (38.8\%) always followed recommended exercise (30 minutes of brisk walking) than middle $(29.2 \%)$ and late $(23.8 \%)$ age groups, and their mean $\mathrm{HbA} 1 \mathrm{c}$ level was $6.8 \%, 7 \%$ and $7.3 \%$, respectively. The correlation coefficient was not found significant between age and exercise compliance.

On blood glucose testing regimen, late (50-60 years) age groups patients were more compliant $(29.8 \%)$ as compared to early $(25 \%)$ and middle (22.2\%) age group patients. Early age group seems to be more compliant to medication, as $88.6 \%$ informed that they always take recommended medicine on time, comparing to middle (86.1\%) and late (84.5\%) age groups patients. Blood glucose testing and medication compliance regimen was also not significantly related with age as shown in
Table 1 . Socioeconomic status accounted for significantly $9.9 \%$ of variance in dietary compliance $\left(\mathrm{R}^{2}=0.099, \mathrm{p}<0.001\right)$. Distribution of patients according to SES revealed that $56.9 \%$ upper class, $45.5 \%$ upper middle, $42.5 \%$ lower middle, $40 \%$ upper lower class and $39.5 \%$ lower class always followed recommended diet. Correlation coefficients revealed that patients of upper SES complied more with dietary regimen than other SES patients $(\mathrm{r}=0.322, \mathrm{p}<0.01)$.

A perusal of the values in Table 2 showed that majority of the patients who always followed recommended exercise regimen were from lower class $(83.3 \%)$ and then from upper class (47.6\%) followed by upper middle (25.7\%) then by lower middle (21.9\%) and upper lower (21.7). Among total sample, 43.5\% (upper lower), 41\% (lower middle) and 36.6\% (upper middle) patients reported that they never practice exercise regimen and their $\mathrm{HbA} 1 \mathrm{c}$ values were $8.3 \%, 8.9 \%$, 8.4\% respectively which was higher than the acceptable range according to IDF [2] (up to $8 \%$ ) and ADA [12] (up to 7\%). The lower class patients were mostly farmer, labor or heavy workers from the occupation and they were always busy in doing physical exertion more than recommended 20-30 minutes of brisk walking. Therefore, majority of lower class patients informed that they always did physical exercise. Exercise regimen was found significantly correlated with Socio-economic status $(r=0.198, p<0.05)$.

Table 2: Distribution of patients according to socioeconomic status on compliance and their mean HbA1c level.

\begin{tabular}{|c|c|c|c|c|c|c|c|c|c|c|c|c|c|c|c|}
\hline \multirow{3}{*}{ Compliance } & \multicolumn{3}{|c|}{ Lower } & \multicolumn{3}{|c|}{ Upper Lower } & \multicolumn{3}{|c|}{ Upper Middle } & \multicolumn{3}{|c|}{ Lower Middle } & \multicolumn{3}{|c|}{ Upper } \\
\hline & \multirow[t]{2}{*}{$\begin{array}{c}\% \text { of } \\
\text { Patie } \\
\text { nts }\end{array}$} & \multicolumn{2}{|c|}{$\begin{array}{l}\text { HbA1c } \\
\text { (in \%) }\end{array}$} & \multirow[t]{2}{*}{$\begin{array}{c}\% \text { of } \\
\text { Patie } \\
\text { nts }\end{array}$} & \multicolumn{2}{|c|}{$\begin{array}{l}\text { HbA1c } \\
\text { (in \%) }\end{array}$} & \multirow[t]{2}{*}{$\begin{array}{c}\% \text { of } \\
\text { Patie } \\
\text { nts }\end{array}$} & \multicolumn{2}{|c|}{$\begin{array}{l}\text { HbA1c } \\
\text { (in \%) }\end{array}$} & \multirow[t]{2}{*}{$\begin{array}{c}\% \text { of } \\
\text { Patie } \\
\text { nts }\end{array}$} & \multicolumn{2}{|c|}{$\begin{array}{l}\text { HbA1c } \\
\text { (in \%) }\end{array}$} & \multirow[t]{2}{*}{$\begin{array}{c}\% \text { of } \\
\text { Patients }\end{array}$} & \multicolumn{2}{|c|}{$\begin{array}{l}\text { HbA1c } \\
\text { (in \%) }\end{array}$} \\
\hline & & Mean & SD & & Mean & SD & & Mean & SD & & Mean & SD & & Mean & SD \\
\hline \multicolumn{16}{|c|}{ Dietary Regimen ( $r=0.322^{* *}, p<0.01$ ) (Regression: $\beta=0.314^{* * *}, R^{2}=0.099, \Delta R^{2}=0.099$ ) } \\
\hline Never & - & - & - & - & - & - & - & - & - & - & - & - & - & - & - \\
\hline Rarely & - & - & - & $4.3 \%$ & 13 & - & - & - & - & - & - & - & - & - & - \\
\hline Sometimes & - & - & - & $8.7 \%$ & 10.9 & 2.89 & $7.6 \%$ & 10.4 & .56 & $8.9 \%$ & 9.8 & 2.48 & - & - & - \\
\hline Usually & $60.5 \%$ & 8.3 & 2.52 & $47 \%$ & 9.0 & 2.07 & $49.9 \%$ & 8.5 & 1.78 & $45.6 \%$ & 8.1 & 1.39 & $43.1 \%$ & 8.8 & 1.65 \\
\hline Always & $39.5 \%$ & 7.4 & 2.19 & $40 \%$ & 8.03 & 2.12 & $42.5 \%$ & 7.4 & 1.10 & $45.5 \%$ & 7.1 & 1.07 & $56.9 \%$ & 7.1 & .79 \\
\hline \multicolumn{16}{|c|}{ Exercise Regimen $\left(r=0.198^{*}, p<0.05\right)$ (Regression: $\left.\beta=0.091, R^{2}=0.008, \Delta R^{2}=0.008\right)$} \\
\hline Never & $16.7 \%$ & 11 & - & $43.5 \%$ & 8.3 & 1.86 & $41 \%$ & 8.9 & 1.82 & $36.6 \%$ & 8.4 & 1.72 & $14.3 \%$ & 6.8 & .57 \\
\hline Rarely & - & - & - & $8.7 \%$ & 10.5 & 3.53 & - & - & - & $2 \%$ & 8.1 & 1.27 & - & - & - \\
\hline Sometimes & - & - & - & $13 \%$ & 10.4 & 3.55 & $4.8 \%$ & 7.0 & 0.16 & $7.9 \%$ & 8.5 & 1.98 & $9.5 \%$ & 9.7 & .35 \\
\hline Usually & - & - & - & $13 \%$ & 8.8 & 1.83 & $32.4 \%$ & 8.2 & 1.54 & $27.7 \%$ & 7.5 & 1.20 & $28.6 \%$ & 8.9 & 2.04 \\
\hline Always & $83.3 \%$ & 7.2 & 1.71 & $21.7 \%$ & 7.9 & 2.63 & $21.9 \%$ & 7.7 & 1.59 & $25.7 \%$ & 7.0 & 1.20 & $47.6 \%$ & 7.7 & 1.15 \\
\hline
\end{tabular}




\section{Current Research in Diabetes \& Obesity Journal}

\begin{tabular}{|c|c|c|c|c|c|c|c|c|c|c|c|c|c|c|c|}
\hline \multicolumn{16}{|c|}{ Blood Glucose Testing Regimen $\left(r=0.157^{*}, p<0.05\right)$ (Regression: $\left.\beta=0.145^{*}, R^{2}=0.021, \Delta R^{2}=0.021\right)$} \\
\hline Never & - & - & - & $4.3 \%$ & 6.4 & - & - & - & - & - & - & - & - & - & - \\
\hline Rarely & - & - & - & $52.2 \%$ & 8.5 & 2.21 & $35.2 \%$ & 8.6 & 1.91 & $21.8 \%$ & 8.0 & 1.83 & $23.8 \%$ & 7.6 & 1.24 \\
\hline Sometimes & $83.3 \%$ & 7.8 & 2.41 & $34.8 \%$ & 9.2 & 2.41 & $30.5 \%$ & 8.4 & 1.82 & $42.6 \%$ & 7.7 & 1.35 & $14.3 \%$ & 8.8 & 1.83 \\
\hline Usually & $16.7 \%$ & 7.9 & - & $8.7 \%$ & 9.5 & 4.38 & $11.3 \%$ & 7.0 & 0.7 & $9.9 \%$ & 8.0 & 1.33 & $19 \%$ & 7.8 & 1.50 \\
\hline Always & - & - & - & $4.3 \%$ & 6.4 & - & $23.6 \%$ & 7.9 & 1.30 & $25.7 \%$ & 7.7 & 1.82 & $42.9 \%$ & 7.1 & .77 \\
\hline \multicolumn{16}{|c|}{ Medication Regimen ( $r=-0.010, p=N S$ ) (Regression: $\beta=0.189^{* *}, R^{2}=0.072, \Delta R^{2}=0.072$ ) } \\
\hline Never & - & - & - & - & - & - & - & - & - & - & - & - & - & - & - \\
\hline Rarely & - & - & - & - & - & - & $3.8 \%$ & 10 & 0.7 & $10.9 \%$ & 6.4 & .49 & - & - & - \\
\hline Sometimes & $16.7 \%$ & 11 & - & - & - & - & $2.9 \%$ & 10.8 & 0.7 & - & - & - & $14.3 \%$ & 7 & .86 \\
\hline Usually & $33.3 \%$ & 6.9 & 1.34 & $13 \%$ & 7.7 & 1.51 & $2.9 \%$ & 7 & 0.7 & $4 \%$ & 9.3 & 2.51 & - & - & - \\
\hline Always & $50 \%$ & 7.4 & 2.19 & $87 \%$ & 8.9 & 2.45 & $90.5 \%$ & 8.2 & 1.69 & $85.1 \%$ & 7.9 & 1.52 & $85.7 \%$ & 8.1 & 1.60 \\
\hline
\end{tabular}

SES accounted for $2.1 \%$ of variance significant at 0.05 level. Results on glucose testing regimen compliance showed that majority of the lower class (83.3\%) sometimes follow glucose testing regimen as compare to other classes. Only $23.6 \%$ from lower middle, $25.7 \%$ from upper middle and $42.9 \%$ from upper class always complied with blood glucose testing when recommended. Patients of higher socioeconomic strata adhered more with glucose testing regimen than other statuses $(r=0.157$, $\mathrm{p}<0.05$ ). Taking into consideration all the SES groups together for assessment according to medication regimen compliance, but the correlation coefficient was not found significant, although SES significantly predicted $7.2 \%$ of the variance in explaining medication compliance.

\section{Discussion}

According to the report of the recent research most of the diagnosed type 2 diabetes patients are in age group of above 40 years, because the manifestations of diabetes are seen in later age years, that is why it is also called adult onset diabetes mellitus [13]. Recent research studies showed that increasing age was related to better compliance $[7,8,14]$. The same results were also documented from research of different geographical regions, for instance, in Caucasian subjects older age patients adhered more with diet and medication regimen and they were less compliant to exercise regimen [6]. Moreover, in Chinese Americans it was also found that old age patients complied better with recommended diet and medication regimen and were more engaged in self-care activities and consequently had low glycosylated hemoglobin and few symptom of diabetes related depression [15]. Furthermore, among Malaysian type 2 diabetic patients attending primary health clinics found that with the increasing age, patients adapted more comfortably to the disease condition and complied better with the medication regimen and so had better control over their blood glucose level [14]. The possible explanation was that the older people might have more concern about their health than younger patients, they can get the necessary help from healthcare providers or family members, and they may be more likely to compliant with therapies. Although a few researchers had found that age was not a factor which causes non-compliance $[6,15]$. It would appear from the studies that the effects of non-compliance for elderly people are not unidirectional. Comparatively young patients and middle aged patients have a lower compliance rate because patients in these two age ranges always have other priorities in their daily life $[16,17]$. Due to their work and other commitments, they may not be able to follow the complex treatment or spend a long time waiting for clinic appointments and follow-up. For older people the non-compliance is unintentional and in most cases it is due to forgetfulness $[7,10]$.

The results about SES revealed the association of high income with high self-care activities including compliance to treatment regimen. It was found that upper SES patients had checked their HbA1c level more often than low income patients [9], and also upper SES patients were more compliant with medication regimen than middle and lower SES patients. Moreover, it was stated that high income was positively related with high self-care ability and low income was associated with low self-care ability [18]. High incomes were also associated with high exercise selfcare activities at well-equipped and leisure environments while lesser income were associated with physical activities in nonleisure environment which includes walking for errands and household work and activities [11]. In Indian socio-cultural scenario the higher rates of lower compliance to non-compliance among low socioeconomic class patients found may be due to poor access to medicine ( high cost), low follow-ups (high medical cost) and unequal distribution of health care facilities and cultural barriers further aggravate the condition [7]. Previous literature also suggested the higher non-compliance among lower SES patients due to illiteracy, poor knowledge and lack of importance of compliance to therapeutic regimen and its impact on health outcome [7]. Only $30 \%$ patients were compliant with the medication regimen in the lower socioeconomic strata which revealed that the non-compliance was likely to be higher in the lower socioeconomic patients than in upper SES patients $[19,20]$. 


\section{Current Research in Diabetes \& Obesity Journal}

\section{Conclusion}

It was concluded that age and SES have significant correlations with glycemic control through better compliance to the recommended regimen and high self-care activities (taking medication on time, comply with diet, self-monitoring blood glucose etc.). With the advancing age, the patient becomes more adjusted with the given regimen and adhered better to it and consequently had better glycemic control. Regarding SES of the patients it was concluded that higher SES patients took great care of themselves through better compliance with the regimen and manage the disease properly.

\section{References}

1. World Health Organization (2016) Global report on diabetes, Switzerland.

2. International Diabetes Federation (2015) IDF Diabetes Atlas. $\left(7^{\text {th }}\right.$ edn), International Diabetes Federation, Switzerland.

3. Hand (1998) Adherence and asthma. In: Mayers LB, Midence K (Eds.) Adherence to treatment in medical conditions. Harwood Academic Publishers, Amsterdam, Netherlands, pp. 383-421.

4. Christensen AJ (2004) Patient adherence to medical treatment regimen: bridging the gap between behavioral science \& biomedicine. Yale university press, New Haven, CT, USA.

5. Brides V, Rapadas J, Sabella W, Sanchez A, Thelshorette J (2012) Compliance of treatment management among diabetes patients. Advancing Nursing Research 4(1): 2094-9537.

6. Shigaki C, Kruse R, Lemaster J, Mehr D, Moore C, et al. (2010) Motivation and diabetes self-management. Chronic Illn 6(3): 202-214.

7. Parajuli J, Saleh F, Thapa N, Ali L (2014) Factors associated with nonadherence to diet and physical activity among Nepalese type 2 diabetes patients; a cross sectional study. BMC Res Notes 7: 758.

8. Santhanakrishnan I, Lakshminarayanan S, Kar SS (2014) Factors affecting compliance to management of diabetes in Urban Health Center of a tertiary care teaching hospital of south India. J Nat Sci Biol Med 5(2): 365-368.
9. Hosler A, Melnik T (2005) Population based assessment of diabetes care and self-management among Puerto Rican adults in New York City. USA. Diabetes Educ 31(3): 418-426.

10. Mukherjee S, Sharmasarkar B, Das KK, Bhattacharyya A, Deb A (2013) Compliance to anti-diabetic drugs: observations from the diabetic clinic of a medical college in Kolkata, India. J Clin Diagn Res 7(4): 661665 .

11. Barrett JE, Plotnikoff RC, Courneya KS, Raine KD (2007) Physical activity and type 2 diabetes. Exploring the role of gender and income. Diabetes Educ 33(1): 128-137.

12. American Diabetes Association (2015) Standards of medical care in diabetes. Diabetes Care 38(1): S1-S93.

13. National Diabetes statistics Report (2014) National Centers for chronic disease prevention and health promotion. USA.

14. Ahmad NS, Ramli A, Islahudin F, Paraidathathu T (2013) Medication adherence in patients with type 2 diabetes mellitus treated at primary health clinics in Malaysia. Patient Prefer Adherence 7: 525-530.

15.Xu Y, Pan W, Liu H (2010) Self-management practices of Chines Americans with type 2 diabetes. Nurs Health Sci 12(2): 228-234.

16. Iihara N, Tsukamoto T, Morita S, Miyoshi C, Takabatake K, et al. (2004) Beliefs of chronically ill Japanese patients that lead to intentional nonadherence to medication. J Clin Pharm Ther 29(5): 417-424.

17. Jin J, Sklar GE, Min Sen Oh V, Chuen Li S (2008) Factors affecting therapeutic compliance: A review from the patient's perspective. Ther Clin Risk Manag 4(1): 269-286.

18. Choi SE (2009) Diet specific social support and glucose control among Korean immigrants with type 2 diabetes. The Diabetes Educ 35(9): 978-985.

19. Kotwani A, Ewen M, Dey D, Iyer S, Lakshmi PK, et al. (2007) Prices and availability of common medicines at six sites in India using a standard methodology. Indian J Med Res 125(5): 645-654.

20. Suranjana B, Debasis R, Shishir K (2013) Analyzing the pattern of prescription noncompliance in patients of cardiac and diabetic clinic of a tertiary care hospital. American Journal of Drug Discovery and Development 3: 106-112.

\begin{tabular}{|l|}
\hline \multicolumn{1}{|c|}{ Your next submission with Juniper Publishers } \\
will reach you the below assets \\
- Quality Editorial service \\
- Swift Peer Review \\
- Reprints availability \\
- E-prints Service \\
- Manuscript Podcast for convenient understanding \\
- Global attainment for your research \\
- Manuscript accessibility in different formats \\
( Pdf, E-pub, Full Text, Audio) \\
- Unceasing customer service \\
Track the below URL for one-step submission \\
https://juniperpublishers.com/online-submission.php \\
\hline
\end{tabular}

